\title{
PONAŠANJE POTROŠAČA PRI ONLAJN GRUPNOJ KUPOVINI TURISTIČKIH USLUGA
}

\author{
Lukrecija Đeri', \\ Nataša Kovačević ${ }^{1}$ \\ Milan Ivkov', \\ Jelena Šuleić
}

'Departman za geografiju, turizam i hotelijerstvo,

Prirodno-matematički fakultet, Novi Sad, Srbija

${ }^{2} \mathrm{~A}$ Hoteli

Correspondence:

Milan Ivkov

e-mail:

milan.ivkov@dgt.uns.ac.rs

\section{Rezime:}

Savremeni način podsticanja prodaje, koji postaje sve popularniji, jeste grupna kupovina. To podrazumeva da se zainteresovani kupci okupljaju na internet mreži, preko sajtova za grupnu kupovinu, i na taj način ostvaruju popust pri kupovini. Internet servis koji pruža uslugu grupne kupovine deluje kao posrednik između prodavca, s jedne strane, i kupca, s druge strane. Poseban fokus rada usmeren je ka ponašanju potrošača - motivima zbog kojih se potrošači opredeljuju ili izbegavaju ovaj vid kupovine. Rezultati do kojih se došlo na osnovu sprovedenog anketnog istraživanja $(n=152)$, pokazuju da su potrošači motivisani za ovaj vid kupovine upravo zbog raznovrsne ponude na jednom mestu, zahvaljujući savremenim internet tehnologijama. Takođe, rezultati pokazuju da se potrošači ne boje zloupotrebe ličnih podataka pri internet kupovini, ali da nisu kupili turističku uslugu jer nisu naišli na adekvatnu ponudu. Ovo zapravo ukazuje da se radi o potrošačima koji su fleksibilniji u odnosu na tradicionalne potrošače. Više od polovine ispitanika zadovoljno je kupljenom uslugom preko interneta i ima nameru da nastavi da kupuje turističke usluge na ovaj način. Takođe, rad nastoji da prikaže demografski profil potrošača grupnih turističkih putovanja u cilju efikasnijih marketinških aktivnosti preduzeća iz turističko-ugostiteljskog sektora.

Ključne reči:

Ponašanje potrošača, grupna kupovina, internet kupovina, turističke usluge.

\section{Ponašanje potrošača}

Potrošač je društveno i kulturno biće. On je istovremeno individua za sebe, član porodice, pripadnik grupe ili određene društvene klase, predstavnik određene nacije, vere, rase itd. Razlozi istraživanja ponašanja potrošača su mnogobrojni. Proučavanje ponašanja potrošača kao posebne marketing discipline počelo je kada su ponuđači shvatili da se potrošači ne ponašaju i ne reaguju uvek u skladu sa pretpostavkom marketing teorije. Mnogi su zanemarivali one proizvode i usluge koje su drugi koristili. Osnovna svrha proučavanja ponašanja potrošača jeste spoznaja zašto i kako potrošači donose svoje odluke o kupovini proizvoda ili usluga. Istraživanje ponašanja potrošača obuhvata brojne oblasti, tj. ono proučava procese $u$ koje su uključeni pojedinci ili grupe kada biraju, kupuju, koriste ili odlažu proizvode, usluge, ideje ili iskustva da bi zadovoljili svoje potrebe i želje. Američka asocijacija za marketing [1] definiše ponašanje potrošača kao dinamičku interakciju spoznaje, ponašanja i činioca okruženja koji rezultiraju u ponašanju i razmeni aspekata života potrošača. Ova definicija uključuje 
sve psihološke, društvene i ponašajuće aspekte potrošača povezujući ih sa spoljnim reakcijama koje se manifestuju u ponašanju potrošača [2]. Ponašanje potrošača postalo je integralni deo strategije planiranja tržišta. Savremeni način podsticanja prodaje, koji postaje sve popularniji, jeste grupna kupovina.

Potrošači u turizmu su vrlo heterogena grupa. Dobro poznavanje i razumevanje ponašanja turista od strane menadžera u turističkoj destinaciji neophodno je za planiranje i primenu efikasnog marketing programa [3].

\section{Grupna kupovina}

Grupna kupovina predstavlja fenomen koji se u poslednjih sedam godina raširio po celom svetu. Koncept grupne kupovine je još relativno nov i nepoznat, stoga je za očekivati porast broja korisnika, kao i proširenje ponude na nove kategorije turističkih proizvoda i usluga. Pravu revoluciju na tržištu popusta doneo je koncept grupne kupovine. To podrazumeva da se zainteresovani kupci okupljaju na internet mreži, preko sajtova za grupnu kupovinu, i na taj način ostvaruju popust pri kupovini. Internet servis koji pruža uslugu grupne kupovine deluje kao posrednik između prodavca, $s$ jedne strane, i kupca, $s$ druge strane. Na pojavu grupne kupovine i na njenu veliku prihvaćenost uticali su u najvećoj meri internet, društvene mreže i recesija. U savremenom svetu marketinga, grupna kupovina postaje sve popularnije sredstvo oglašavanja [4].

Koncept grupne kupovine je vrlo jednostavan. Internet servis koji pruža uslugu grupne kupovine deluje kao posrednik između prodavca, $s$ jedne strane, i kupca, $s$ druge strane. Servis u saradnji sa prodavcima dogovara koji će se proizvodi i usluge naći u ponudi, koliki će popust odobriti na ponudu, te koliko je minimalno potrebno zainteresovanih osoba kako bi ponuda postala važeća. Nakon toga, servis objavljuje ponudu na svojoj internet stranici. Ukoliko se prijavi dovoljan broj ljudi za kupovinu određenog proizvoda ili usluge, svi prijavljeni dobijaju od prodavca veliki popust. Prodavci uglavnom odobravaju popust od 50\% do 70\%, a minimalan broj zainteresovanih osoba određuje se tako da se pređe prag isplativosti. Za neke proizvode i usluge potrebno je svega pet do deset zainteresovanih ljudi kako bi ponuda postala važeća. Takođe, prodavci u saradnji sa internet servisom mogu odrediti i maksimalan broj ljudi koji se mogu prijaviti za određenu ponudu [5].

Nakon što postane uspešna, svaka ponuda ima određeni vek trajanja. Uglavnom je reč o dnevnim ponudama ili do nedelju dana trajanja. Kupac koji je kupio proizvod ili uslugu iz ponude, na e-mail adresu prima kupon koji mu omogućava da ostvari popust.

Servis za grupnu kupovinu svakog dana predstavlja novu ponudu, a kako neke ponude traju i po nekoliko dana, $\mathrm{u}$ istom trenutku moguće je više aktivnih ponuda. Većina servisa, kako bi privukli veći broj korisnika usluga osim što objavljuju ponudu dana na svojim internet stranicama, takođe nudi i mogućnost informisanja o ponudi dana putem elektronske pošte, popularnih društvenih mreža, sms poruke [4].

Objavljivanje informacija o proizvodima i uslugama na veb-sajtu za grupnu kupovinu predstavlja poziv korisniku da učini ponudu klikom na dugme/taster „kupi“. Ukoliko sajt prihvati ponudu korisnika nastaje ugovorni odnos i korisnik preuzima ugovornu obavezu da plati izabrani proizvod ili uslugu. Prodaja može biti ograničena na maksimalni broj korisnika zainteresovanih za određeni turistički proizvod ili uslugu. Korisnik plaća proizvod ili uslugu putem poštanskih uplatnica, interneta ili na neki drugi elektronski način ponuđen na sajtu.

Grupna kupovina podrazumeva postojanje sajtova preko kojih mnoštvo ljudi može da rezerviše određene turističke proizvode i usluge po sniženim cenama, ukoliko sa njihovim ponuđačima sajt ima dogovor.

U Srbiji je sve više ovakvih sajtova, dok u razvijenim društvima „pametni potrošači” već godinama kupuju na ovaj način (preko Groupon u SAD-u, CityDeal i DailyDeal u Nemačkoj, i dr.). Jedan od domaćih sajtova [6], vodi se motom da je "puna cena samo početni broj, a cena sa popustom je aktuelna vrednost" i na taj način možda objašnjava i suštinu grupne kupovine.

U Srbiji se prvi sajtovi grupne kupovine pojavljuju 2010. godine. Po proverenom copy/paste receptu, za veoma kratak period doživeli su veliku popularnost. Počeo je sa tri ovakva servisa (KupiMe.rs, Popusti.rs, Kolektiva. $r s$ ), da bi do kraja 2011. imao oko 40 sajtova. Istraživanje koje je sproveo portal Agregato.com među 18.000 internet korisnika, kao ubedljivo najpopularniji vid ponuda na sajtovima grupne kupovine izdvaja turistička putovanja sa oko $40 \%$, sledi kupovina garderobe sa oko $22 \%$, u manjoj meri usluge zabave, lepota [7].

\section{METODOLOGIJA}

Na teritoriji AP Vojvodine, u prvoj polovini 2015. godine, na uzorku od 150 ispitanika, za potrebe boljeg razumevanja ponašanja potrošača prilikom grupne kupovine turističkih putovanja, njihovih budućih namera kupovine, razloga opredeljenja za ovu vrstu kupovine i 
ostalog spovedeno je anketno istraživanje, kojim se došlo do zanimljivih rezultata. Anketa se sastoji od 19 pitanja, prva grupa pitanja odnosi se na socio-demografske karakteristike ispitanika, zatim se pitanjima nastojalo doći do odgovora o načinu saznanja o konceptu grupne kupovine, da li su do sada ispitanici vršili kupovinu ovim putem, najčešće korišćeni sajtovi, način informisanja o ponudi, da li je putovanje bilo u skladu sa njihovim očekivanjima, da li imaju nameru u budućnosti da učestvuju u grupnoj kupovini, motivacija za kupovinu i razlog nekupovine turističkih putovanja na ovaj način.

Uzorak uzet kao osnov istraživanja bio je prost slučajan. Dobijeni podaci obrađeni su u statističkom paketu SPSS 17.

Osim analize socio-demografskih karakteristika ispitanika, metodom Hi-kvadrat test (Chi-square test) testirana je veza dve kategorijske promenljive. Poređena je učestalost slučajeva u raznim kategorijama jedne promenljive (polna struktura i bračni status) sa raznim kategorijama druge promenljive.

\section{REZULTATI ISTRAŽIVANJA}

Domaći servisi u svom poslovanju slede proverene prakse stranih servisa za grupnu kupovinu, kao što su lokalna orijentacija, obaveštavanje korisnika o ponudi dana putem elektronske pošte i društvenih mreža, mogućnost poklanjanja proizvoda i usluga iz ponude itd. [8].

Rezultati ukazuju da je većina ispitanika saznala za ovaj servis preko prijatelja (53\%), što objašnjava i brzinu popularizacije ovog načina kupovine. Visok udeo je i onih koji su preko društvenih mreža došli do saznanja o postojanju i načinu funkcionisanja grupne kupovine u Vojvodini (28\%). Preko pretraživača je 14\% ispitanih saznalo za servis, a na ostale načine preostalih $5 \%$.

Koncept grupne kupovine u Srbiji proteklih godina postao je veoma popularan i ima tendenciju rasta. $\mathrm{Na}$ srpskom tržištu trenutno postoji 44 kompanije koje rade kao servis za grupnu kupovinu. Između 2009. i 2011. godine otvoreno je 35, od toga 59\% u 2011. godini [9].

Da je u Srbiji ovaj koncept zaživeo, jasno pokazuju podaci da su čak $61 \%$ ispitanih već kupovali turistička putovanja preko servisa za grupnu kupovinu.

Rezultati pokazuju da je najveći broj onih koji su se informisali o popustima pretražujući internet stranice sajtova za grupnu kupovinu. Njihovo učešće je $48 \%$ u odnosu na ukupan broj ispitanika. Nešto manje ispitanika informisalo se preko elektronske pošte (36\%). Samo 16\% ispitanika je do informacije o ponudama došlo preko prijatelja ili poznanika koji su im prosledili informacije.
Najviše je onih koji su samo jednom koristili ove usluge i imaju učešće od $46 \%$ u odnosu na ukupan broj ispitanika. Nešto manje je onih koji su kupovali od dva do četiri puta (43\%), od četiri do šest puta kupovalo je $7 \%$ ispitanih, dok je po $2 \%$ onih koji su kupovali od šest do osam puta i onih koji su kupovali više od osam puta.

Više ispitanika kupovalo je putovanja u inostranstvo (44\%), a $41 \%$ njih opredelio se za putovanja u okviru Srbije. Preostalih 15\% ispitanika kupovali su i jedna i druga putovanja.

Analizom zadovoljstva korisnika usluga sajtova za grupnu kupovinu došlo se do veoma dobrih rezultata koji ukazuju da je čak $86 \%$ ispitanika imalo pozitivno iskustvo, jer je putovanje bilo u skladu sa njihovim očekivanjima. Samo 9\% ispitanika očekivalo je više u odnosu na doživljeni kvalitet usluge, dok je 5\% onih čija su očekivanja prevaziđena.

Da je većina ispitanika voljna da i dalje koristi usluge sajtova za grupnu kupovinu prikazuju rezultati na grafikonu broj 17. Čak 75\% ispitanika izjasnilo se da bi opet kupilo kupon za putovanje, dok je samo $2 \%$ onih koji ne žele više da putuju na ovaj način. Neopredeljenih je 23\%.

Kao što se i očekivalo, najveći udeo kupaca motivisan je uštedom novca i njih je 38\% u odnosu na ukupan broj ispitanika. Praktičnost kupovine motivisalo je $17 \%$ ispitanika, dok je $21 \%$ odgovorilo da je ovaj vid kupovine sigurna kupovina po nižoj ceni. Ulaganje manje napora u potrazi za mestom putovanja motivisalo je $24 \%$ ispitanih.

Raznovrsnost ponude na jednom mestu je jak motiv za kupce na sajtovima za grupnu kupovinu. Čak 98\% ispitanika saglasno je sa tom izjavom, dok je preostalih $2 \%$ smatralo da im raznovrsnost ponude nije dovoljno jak motiv.

Koliko su snižene cene značajan faktor pri kupovini turističkih putovanja na sajtovima za grupnu kupovinu, govori podatak da ispitanici koji su stimulisani sniženim cenama imaju učešće od $55 \%$, dok je $45 \%$ onih koji imaju potrebu za putovanjem, te im je ponuda po nižim cenama bila samo dodatni stimulans u odabiru.

Najviše ispitanika motivisano je potrebom za promenom svakodnevnice i imaju učešće od 50\%. Društvo je motivisalo $24 \%$ ispitanika, dobar provod $13 \%$ ispitanika, upoznavanje novih ljudi $9 \%$ ispitanika, dok je po $2 \%$ onih koji su motivisani šopingom i ostalim razlozima.

Razlog zbog kojeg ispitanici nisu koristili usluge sajtova za grupnu kupovinu su različiti. Ispitanici koji još uvek nisu našli interesantnu ponudu uzimaju učešće od $30 \%$, zatim su po $22 \%$ ispitanika od onih koji ne znaju kako se to radi i onih koji smatraju rizičnom kupovinu 
nečeg što nisu videli, $14 \%$ ima strah od plaćanja preko interneta, 7\% ispitanika nema pristup internetu, dok 5\% ne želi da ostavlja podatke onlajn.

Rezultati Hi-kvadrat testa nezavisnosti između promenljivih, u ovom slučaju pola ispitanika sa raznim kategorijama drugih promenljivih, ukazuju da vrsta pola nema veliki uticaj na način saznanja o konceptu grupne kupovine, izvor informacija o ponudama, područje putovanja, na zadovoljstvo kupljenim putovanjem i na druge kategorije. Jedina značajnost pokazala se u odnosu pola ispitanika sa izborom sajta grupne kupovine i razlozima nekupovine turističkih putovanja preko koncepta za grupnu kupovinu. Pokazalo se da pol ima uticaj pri izboru sajta servisa za grupnu kupovinu, kao i na nekupovinu turističkih putovanja, da li zbog neznanja korišćenja servisa, neposedovanja pristupa internetu, bojazni za ostavljanjem podataka onlajn, straha plaćanja preko interneta, rizika od neviđene kupovine, ili da još uvek nije pronađena adekvatna ponuda. Svakako da prikazana značajnost u odnosu pola i razloga nekupovine turističkih proizvoda i usluga proizilazi iz mentaliteta i psiholoških karakteristika potencijalnih korisnika.

Rezultati dobijeni metodom Hi-kvadrat testa nezavisnosti, gde je za jednu promenljivu uzet bračni status za poređenje učestalosti slučajeva u odnosu na razne kategorije drugih promenljivih, ukazuju da bračni status nema veliku značajnost na izbor sajta za grupnu kupovinu, zadovoljstvo kupljenim putovanjem, područje putovanja, i druge kategorije.

Međutim, bračni status ima značajne veze sa načinom saznanja o konceptu grupne kupovine, razlozima nekupovine turističkih putovanja i time da li su do sada kupovali putovanja preko servisa za grupnu kupovinu. Značajnost u odnosu bračnog statusa (udata/oženjen, razveden/a, u braku sa ili bez dece i drugo) i načina informisanja o konceptu grupne kupovine, svakako proizilazi iz socijalnih karakteristika korisnika usluga, da li su informisani preko prijatelja, pretraživača, preko društvenih mreža i ostalo. Zatim, saznanje da je značajan uticaj bračnog statusa na razloge nekupovine turističkih putovanja od velike je važnosti, pogotovo za marketing eksperte u cilju pronalaženja strategija za smanjenjem razloga nekupovine turističkih proizvoda i usluga i pronalaženjem načina za zadovoljenje njihovih potreba i želja. Uticaj bračnog statusa ogleda se i na samu kupovinu turističkih putovanja preko servisa za grupnu kupovinu (da li jesu ili nisu kupovali putovanja), to je još jedan zadatak za marketing eksperte da uvide razloge za nekupovinu turističkih proizvoda i usluga. Verovatno da glavni razlozi leže u ekonomskoj situaciji potencijalnih korisnika usluga, jer na primer razvedena majka sa troje dece manje će kupovati, ili neće uopšte kupovati, turistička putovanja, iako je samim konceptom grupne kupovine ista snižena dodatno i do $70 \%$. Dok, na primer, neudata, zaposlena i savremena mlada žena verovatno spada u grupu onih koji kupuju turistička putovanja preko koncepta grupne kupovine.

\section{ZAKLJUČAK}

Značaj grupne kupovine sa stanovišta potrošača najviše se ogleda u ekonomskim razlozima zahvaljujući sniženim cenama turističkih proizvoda i usluga, kao i raznovrsnosti ponude na jednom mestu, što u velikoj meri utiče na vreme neophodno za izbor i kupovinu proizvoda ili usluge.

Većina ispitanika koji su upoznati sa ponudama sajtova za grupnu kupovinu srednjeg su životnog doba, $\mathrm{u}$ radnom odnosu i sa fakultetskom diplomom, što ukazuje da je ovde reč o savremenim potrošačima koji znaju šta žele od putovanja.

Kao što je i očekivano, na osnovu anketnog istraživanja potvrđeno je da su turisti motivisani za ovaj vid kupovine upravo raznovrsnošću ponude na jednom mestu. Razlog tome je savremen način života koji utiče na nedostatak vremena za kupovinu turističkih putovanja na tradicionalan način.

Ovim istraživanjem takođe se pokazalo da više ispitanika nije kupilo turističku uslugu jer nije naišlo na adekvatnu ponudu, a ne zbog pronevere podataka, što zapravo ukazuje da se radi o savremenim potrošačima upoznatim sa ovim načinom plaćanja, odnosno kupovine.

Od velike važnosti za koncept grupne kupovine turističkih putovanja je podatak da je više od polovine ispitanika zadovoljno kupljenom uslugom preko grupne kupovine i ima nameru da i u budućnosti prati trend te vrste kupovine. Razlog tome su, pre svega, savremeni potrošači, koji sve više imaju predstavu o tome šta očekuju od putovanja i na koji način da dođu do potencijalno kvalitetnih ponuda, kao i atraktivne i snižene ponude koje su animirale korisnike da počnu da kupuju na ovaj novi način, bez obzira na averziju prema plaćanju platnim karticama na internetu

Grupna kupovina turističkih proizvoda i usluga motiviše turiste iz Srbije na kupovinu, pre svega, širokim izborom ponuda i nižim cenama. Koncept grupne kupovine je još relativno nov i neotkriven, stoga je i za očekivati rast broja korisnika u budućnosti. 


\section{LITERATURA}

[1] www.ama.org

[2] L. Đeri, Ponašanje potrošača na turističkom tržištu. Novi Sad: Prirodno-matematički fakultet, Departman za geografiju, turizam i hotelijerstvo, 2013.

[3] Đ. Ozretić Došen, D. Prebežac, "Ponašanje potrošača u turizmu-stavovi i motivacijski čimbenici kao kriterij segmentiranja turističkog tržišta”, Acta Turistica. Zagreb, vol. 15(2), pp. 118143, 2003.

[4] I. Štulec, K. Petljak, "The research on buying behaviour among group buyers: the case of Croatia", International Journal of Knowledge-Based Development, vol. 4(4), pp. 382-401, 2013.
[5] J. Sruk, "Zadovoljstvo grupnom kupovinom pružatelja ugostiteljskih usluga”, Neobjavljeno.

[6] www.grupovina.com

[7] D. Miličić, "Načini za pospešivanje prodaje putem grupne kupovine" Neobjavljeno.

[8] K. Petljak, I. Štulec, "Moć grupne kupovine”, Suvremena trgovina, vol. 35(6), pp. 24. 2010.

[9] M. Šehović, K. Vukićević, M. Tasić, “Group buying in Serbia: necessity or just marketing?", Proceedings of the XIII International Symposium SymOrg, pp. 1171-1176, June 2012. 